\title{
Adnan Menderes Üniversitesi Merkez Kütüphanesi Gelişimi ve Hizmetleri
}

\section{Adnan Menderes University Library: History and Services}

\section{Altan Çolakkol}

\section{Öz}

Bu makalede, Adnan Menderes Üniversitesi Kütüphanesi'nin gelişimi, görevleri, verdig̈i hizmetler ve geleceğe yönelik hedefleri anlatılmaktadir.

Anahtar säzcükler: Üniversite kütüphaneleri, Kütüphane tanitımı, Kütüphane hizmetleri, Adnan Menderes Üniversitesi Kütüphanesi.

\section{Abstract \\ This paper described the Adnan Menderes University Central Library's development, missions, services and future aims.}

Keywords: University library, Library publicity, Library services, Adnan Menderes University Central Library.

\section{Giriş}

Adnan Menderes Üniversitesinin (ADÜ) eğitim, öğretim ve araştırma faaliyetleri doğrultusunda gerekli her türlü bilgi ve belgeyi sağlamak, düzenlemek ve bu kaynaklardan en iyi şekilde faydalanılmasını amaç edinen Merkez Kütüphane, 1993 yılı sonlarında Dokuz Eylül Üniversitesi Turizm İşletmeciği ve Otelcilik Yüksek Okulu Kütüphanesi devir alınarak kurulmuştur.

Kütüphanenin temeł işlevi, hızla ve değişik ortamiarda artan bilginin toplanarak düzenlenmesi, eğitim ve araştırma sürecinde hizmete sunulmasıdır. Bunun yanı sıra bilgiye erişim için ülkemizdeki ve dünyadaki bilimsel ve tek-

- Uzman Kütüphaneci; Adnan Menderes Üniversitesi Küłüphane ve Dokümantasyon Daire Başkanigig), (acolakkol@adu.edu.tr). 
nolojik yenilikleri izleyerek verilen hizmetlere uyarlamak çabası ile kullanıcılara bilgi aktarma hizmetini gerçekleştirmektedir.

\section{ADÜ Merkez Kütüphanesinin Kuruluşu ve Gelişim Süreci}

Adnan Menderes Üniversitesinin kuruluşu ile birlikte, Dokuz Eylül Üniversitesi Turizm İşletmeciği ve Otelcilik Yüksek Okulunun Kütüphanesi, Merkez Kütüphane haline dönüştürülmüştür. Kütüphanenin yeniden yapılanması ve gelişim süreci kronolojik olarak şöyle özetlenebilir:

1993 - Kuruluş.

- Kitap ve süreli yayın koleksiyonu oluşturulmaya başlanmıştır.

1994 Kütüphane otomasyon çalışmalarının başlangıcı olarak KUTUPB otomasyon programı satın alınmıştır.

- Kütüphane Yönetmeliği hazırlanarak Resmi Gazete'de yayınlanmıştır.

1995 - İlk Internet bağlantısı, Bilgi İşlem Daire Başkanlığı kurulmadan önce, Kütüphane ve Dokümantasyon Daire Başkanlığınca gerçekleştirilmiştir.

1996 - Kütüphane ve Dokümantasyon Daire Başkanlığı Web Sitesi hazırlanarak Internet'te yayımına başlanmıştır (http://kutuphane.adu.edu.tr).

1997 Elektronik dergi ve veri tabanı abonelikleri gerçekleştirilmiştir.

1999 - Kütüphane otomasyon programı, Internet arayüzü sürümüne sahip olan KUTUPMW ile yenilenerek, çevrimiçi katalog uzaktan erişime açılmıştır.

- Elektronik veri tabanı abonelikleri, ulusal bir konsorsiyum olan ANKOS'la (Anadolu Üniversite Kütüphaneleri Konsorsiyumu) birlikte yapılmıştır.

1 "Adnan Menderes Üniversifesi Kütüphaneler Yönetmeligi" T.C. Resmi Gazete (21876, 16 Mant 1994): s. 23 27. 
2001 Kütüphane için tasarlanmış bir yapıya taşınarak hizmetlerinin daha etkin biçimde kullanıcıya sunulması sağlanmışı̆ır.

- ADÜ'nin ev sahipliğinde, ÜNAK işbirliği ile “Kütüphanelerde Web Sitesi Hazırlama ve Uygulama Semineri" yapılmıştır.

\section{Bilgi Kaynaklan!}

Kütüphane yönetimi, kullanıcıların ihtiyaç duyduğu ve duyabileceği her tür kitap, süreli yayın, CD-ROM, kaset ve elektronik bilgi kaynağını sağlamaya çalışmaktadır. Kütüphane koleksiyonunda Kasım 2001 tarihi itibariyle, 15.000 ciltten fazla kitap, 684 başık süreli yayın, 35 adet kaset, 39 adet kitap CD-ROM'u, 7 adet CD-ROM veri tabanı, 2 adet çevrimiçi veri tabanı bulunmakta ve kullanıcı istekleri doğrultusunda yeni kaynaklar sağlanarak bu sayı artırılmaktadır.

\section{Bina}

Kütüphane, kuruluş aşamasında Fen-Edebiyat Fakültesinin giriş katında $240 \mathrm{~m}^{2}$ lik bir alanda hizmet vermiş, 26.06.2001 tarihinde kütüphane binası olarak yapılan yeni yerine taşınmıştır. Bilgi teknolojilerinin çağdaş olanakları ile donatılan yeni bina, $2000 \mathrm{~m}^{2}$ lik bir alana sahiptir. Girş̧ katında; danışma ve ödünç verme hizmetleri verilmektedir. Bu alanda, danışma ve bilgi tarama hizmeti veren birimler, okuma salonu, 14 adet kişisel bilgisayara sahip Internet salonu ve CD-ROM tarama salonu yer almaktadır. Ayrıca, teknik işlemlerin yürütüldüğü kataloglama ve sınıflama, sağlama, kitap cilt ve barkod işlemleri de bu katta yürütülmektedir. Binanın ikinci katında ise, idari bürolar ile süreli yayınlar salonu ve çok amaçlı eğitim salonu bulunmaktadır.

\section{Organizasyon ve Personel}

Kütüphane ve Dokümantasyon Daire Başkanlığı altında yürütülen bilgi hizmetleri; teknik hizmetler, okuyucu ve bilgi hizmetleri, idari hizmetler olmak üzere üç ana grupta yapılandırıımıştır. 2001 yılı sonu itibariyla, bu organizasyon içinde halen bir daire başkanı, beş uzman kütüphaneci, bir şef, bir memur, iki hizmetli ve yarı zamanlı çalışan iki öğrenci ile yürütülen hizmetler, etkin ve verimli biçimde verilmeye çalışılmaktadır. 


\section{Kütüphane Hizmetleri}

Kütüphane hizmetleri, teknik hizmetler ve okuyucu ve bilgi hizmetleri olmak üzere iki ana grupta toplanmıştır. Teknik hizmetler kapsamında sağlama, kataloglama ve sınıflama, süreli yayınlarla ilgili işlemler; okuyucu ve bilgi hizmetleri kapsamında ise danışma, ödünç verme, elektronik bilgi erişim hizmetleri ve kütüphanelerarası işbirliği bulunmaktadır.

\section{Teknik Hizmetler}

Sağlama hizmeti, genellikle araştırmacıların istekleri doğrultusunda satın alma yoluyla veya bağış olarak gelen kaynakłarın koleksiyona alınması ile yapılmaktadır. Koleksiyondaki toplam 15.000 adet kitabın 1/3'ü, 1993 yılından itibaren kütüphaneye gönderilen bağışlar yoluyla sağlanmıştır.

Kataloglama ve sınıflama işlemlerinde, kütüphane kaynakları Anglo American Kataloglama Kuralı 2 esas alınarak kataloglanmakta, Kongre Kütüphanesi Sınıflama Sistemi (Library of Congress Classification System) ve Kongre Kütüphanesi Konu Başlıkları (Library of Congress Subject Heading) kullanłlarak sınıflanmaktadır. Kaynaklar, kütüphane içinde açık raf sistemine göre yerleştirilmekte ve okuyucular tarafından serbest kullanımı özendirilmektedir.

Kütüphane koleksiyonunda bulunan kaynaklara ait tüm bilgiler, kütüphane otomasyon programı "KUTUPMW" ile tutulmaktadır. Program, 2001 yilı içerisinde bir üst sürüm ile yenilenerek, kütüphane kataloğu Internet üzerinden erişilebilir hale getirilmiştir.

Süreli yayın koleksiyonu, 2000 yılına kadar ancak bağış ve değişim yoluyla oluşturulurken, 2001 yılından itibaren 23 yabancı, 64 Türkçe süreli yayına abone olunmuştur. Kamu kurum ve kuruluşları ile eğitim kurumlarından 530 adet süreli yayın bağış olarak geimeye devam etmektedir. Süreli yayınların bilgilerì de, kütüphane otomasyon programına aktarılmakta ve Internet üzerinden erişilmektedir.

\section{Okuyucu ve Bilgi Hizmetleri}

Danışma biriminde, kullanıcılara kütüphane hakkında genel bilgi, katalog sorgulama terminallerinin kullanımı ve aradıkları bilgilere ulaşabilmeleri için uygun birime veya kaynağa yönlendirme gibi hizmetler verilmektedir. Ayrıca 
istekler doğrultusunda kütüphane ile ilgili her türlü bilgilendirme ve kullanıcı eğitimi de yapılmaktadır.

Ödünç verme hizmeti, kütüphane koleksiyonundaki danışma niteliğinde olmayan basılı kaynaklardan, personele ve öğrencilere kütüphane dışında da yararlanma olanağı sağlanmaktadır. Bir defada akademik personele beş, idari personel ve öğrencilere üç adet kaynak, bir ay süreyle ödünç verilmektedir. 2001 yılı içerisinde, 1.619 akadernik personel, 8.691 öğrenci, 189 idari personel olmak üzere toplam 10.499 okuyucu ödünç verme hizmetinden yararlanmıştır.

Elektronik bilgi erişim hizmetleri sayesinde, fiziksel ortamda verilen hizmetlerden teknolojik açıdan uygun olanları Internet üzerinden erişilebilir duruma getirilmiştir. Kütüphane otomasyonunun ikinci aşaması olan bu süreç, geleceğin kütüphanecilik anlayışı olacağı anlaşılan elektronik kütüphanecilik çalışmalarına ADÜ Kütüphanesinde de başlanması anlamına gelmektedir. Bu amaçla kütüphane web sitesi hazırlanmış; danışma, güncel duyuru, kütüphane katalogunun Internet üzerinden erişimi, çevrimiçi dergiler ve veri tabanları abonelikleri ile elektronik ortamdan da hizmet verilmeye başlanmışır. Ayrıca ADÜ'de yapılan tezlerin bibliyografik kimliklerine ve özlerine, yeni yapılan tezlerin ise tam metinlerine, kütüphane web sitesine üzerinden erişilmektedir. Böylece Web sitesinden kütüphane kataloguna, tezlere, serbest ve abone olunan elektronik dergilere, ansiklopedilere, sözlüklere ve veri tabanlarına erişebilmekte, yerli ve yabancı basına, popüler arama motorlarına ve diğer bilgi merkezlerine de bağlantılar yapılarak Internet'teki bilgi kaynaklarından daha geniş biçimde yararlanma olanağı yaratılmaya çalışılmaktadır.

Kütüphanelerarası iş̧irliği kapsamında, diğer bilgi merkezleri ve kütüphanelerle işbirliği yapılarak; ödünç kitap alma-verme, fotokopi sağlama hizmetleri verilmektedir. Ayrıca araştırmacıların yayın ve atıf taraması isteklerinde kütüphane kaynakłarı yeterli olmadığında, diğer kütüphanelerden destek alınarak karşılanmaktadır.

\section{Sonuç}

Adnan Menderes Üniversitesi Merkez Kütüphanesinin, bilgi kaynaklarının kullanımını etkileyen en önemli problemlerin başında dağınık bir yapıya sa- 
hip olması nedeniyle, yer ve ulaşım sorunları gelmektedir. Bu problemi ortadan kaldısmak amacı ile elektronik kütüphanecilik çalışmalarına ağırlık verilerek kullanıcıya daha geniş ve etkin bilgi hizmeti sunmak amaçlanmaktadır. Böylece ADÜ Merkez Kütüphanesi, bilgi hizmetlerinde teknolojiyi ve kaliteyi yakalamayı hedefleyen elektronik bir bilgi merkezi olma bilinci içinde çalışmalarını sürdürmektedir. 